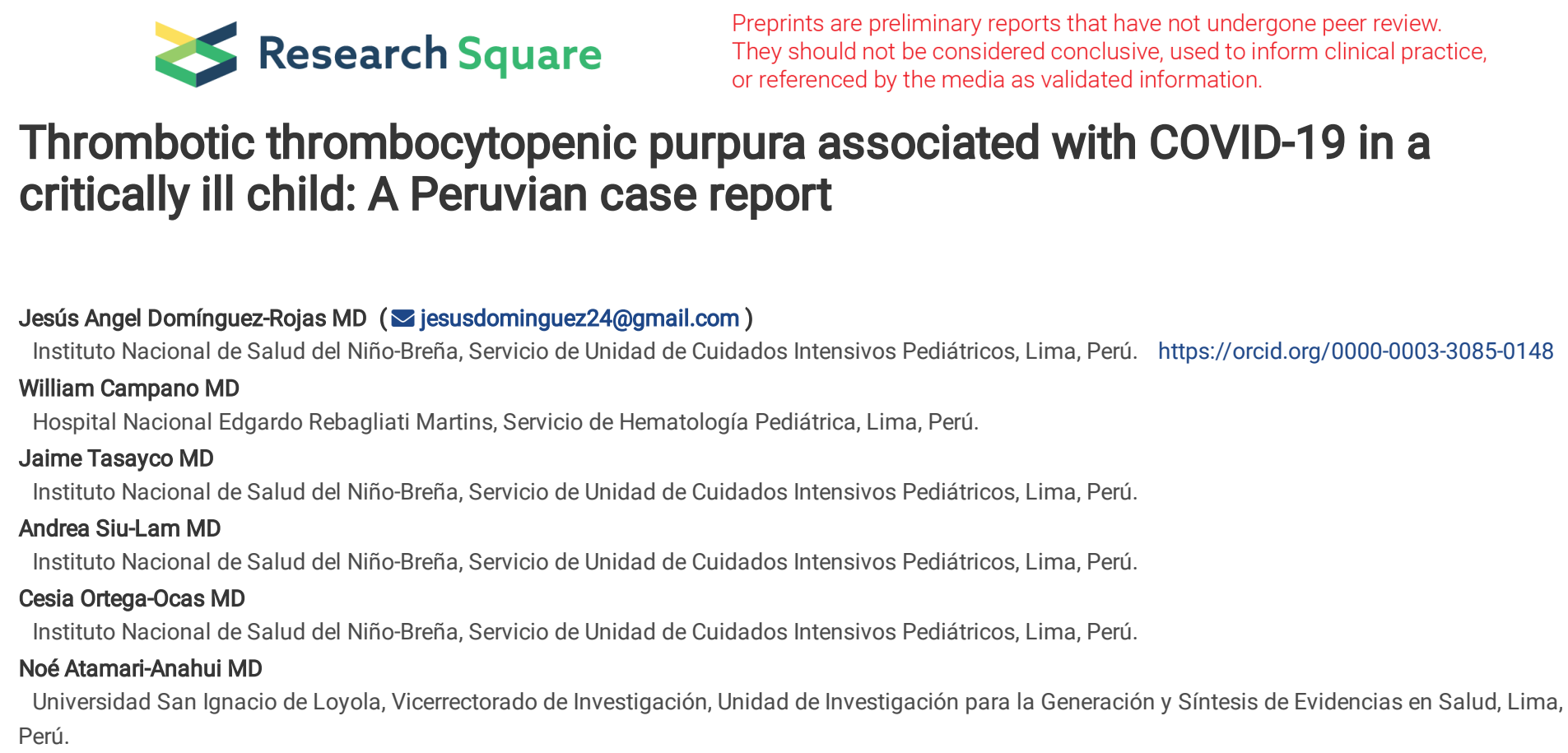

\section{Thrombotic thrombocytopenic purpura associated with COVID-19 in a critically ill child: A Peruvian case report}

Version of Record: A version of this preprint was published at Boletín Médico del Hospital Infantil de México on January 25th, 2022. See the published version at https://doi.org/10.24875/BMHIM.21000061. 


\section{Abstract \\ Background}

Acquired thrombotic thrombocytopenic purpura (TTP) is a rare disease. This pathology requires necessary resources for its diagnosis, especially in the context of the pandemic by the new SARS-CoV-2 coronavirus due to the lack of diagnostic tests and the variable response to plasma exchange in middle and lowincome countries.

\section{Case report:}

We report a case of a 9-year-old Hispanic boy with SARS-CoV-2 (IgG) infection, with atypical presentation and multisystemic involvement, thrombotic microangiopathy, dermal manifestations, hematologic, kidney, and neurologic involvement. Post SARS-CoV-2 infection evolution, application of the PLASMIC score, and genetic study were performed. Ventilatory and hemodynamic support, corticotherapy, immunoglobulins, plasma exchange, renal replacement therapy, and monoclonal antibodies were given without favorable response.

\section{Conclusions}

TTP associated with SARS-CoV-2 is infrequent in the pediatric population. Necessary resources are needed to make the diagnosis and maintain the necessary support and management to avoid fatal outcomes.

\section{Introduction}

Thrombotic microangiopathy (MAT) is characterized by microthrombus formation associated with subsequent thrombocytopenia, microangiopathic hemolytic anemia (MAHA), and target organ injury (1). Thrombotic microangiopathies are a group of disorders that are primarily related to endothelial dysfunction. This category of endothelial dysfunction results from various imbalances between platelet, endothelial, immune system, and cytokine production (2). Thrombotic thrombocytopenic purpura (TTP) is a rare fatal condition among hematological diseases characterized by microvascular thrombosis with platelet aggregation in a patient with severe functional deficiency of ADAMTS13 (activity< $10 \%)(3)$.

COVID-19 is a new disease with different clinical manifestations that affect children (4). During SARS-COV-2 infection, hematological diseases such as immune thrombocytopenia and TTP were described in adults $(2,5)$. However, in children, the information is still limited. Hidalgo et al. reported a 14 -year-old with COVID-19 associated TTP, with a favorable outcome after treatment with plasma exchange therapy (PEX) (6). Verma et al. described another case of COVID-19 complicated by haemophagocytic lymphohistiocytosis and TTP in a 21-year-old man, who died despite treatment (7). The objective of the article is to describe this unusual presentation of TTP associated with COVID-19 in a pediatric patient with a fatal outcome.

\section{Case Report}

A 9-year-old male, Hispanic, presented to the pediatric emergency department with abdominal pain and fever of 14 days of evolution. Maternal family contact 5 weeks ago RT-PCR SARS-CoV-2 positive and the patient's serological test for SARS-CoV-2 antibodies at hospital admission was positive (IgG). He had no previous hospitalizations, no reports of illnesses or surgical interventions and complete immunizations. Vital functions on admission were heart rate 120 beats/minute, respiratory rate $22 /$ minute, temperature $38^{\circ} \mathrm{C}$, weight $30 \mathrm{~kg}$, height $128 \mathrm{~cm}$. On clinical examination, there was the pallor of the skin and mucous membranes, chapped lips, macular erythematous lesions symmetrically distributed on the neck, forehead, and groin area. The abdomen was painful to palpation in the mesogastrium. Her labs showed hemoglobin $11 \mathrm{~g} / \mathrm{dL}$, leukocytes $18.9 \times 10^{3} / \mathrm{uL}$, platelets $528 \times 10^{3} / \mathrm{uL}$, C-reactive protein $4.6 \mathrm{mg} / \mathrm{dL}$, normal coagulation profile, fibrinogen $488 \mathrm{mg} / \mathrm{dL}$, lactate dehydrogenase $1317 \mathrm{U} / \mathrm{L}$, D-dimer $1.6 \mathrm{mg} / \mathrm{L}$, complement C3 and C4 normal, urea $18 \mathrm{mg} / \mathrm{dL}$, creatinine 0.4 $\mathrm{mg} / \mathrm{dL}$, albumin $3.7 \mathrm{~g} / \mathrm{dL}$, triglycerides $130 \mathrm{mg} / \mathrm{dL}$, creatine kinase $25 \mathrm{mg} / \mathrm{dL}$, ferritin $538 \mathrm{ng} / \mathrm{mL}$, serum electrolytes with normal values and the urine test showed hematuria. Abdominal ultrasound showed hepatomegaly and echocardiography without alterations. He received exogenous human immunoglobulin $2 \mathrm{gr} / \mathrm{kg} /$ day, acetylsalicylic acid $3 \mathrm{mg} / \mathrm{kg} /$ day for 7 days, prednisone $2 \mathrm{mg} / \mathrm{kg} /$ day for 5 days for the probable multisystemic inflammatory syndrome. On the second day of treatment, she was afebrile and on the fourth day the erythematous lesions decreased, there was an absence of hematuria and a decrease in acute phase reactants, with the indication for discharge home. Five days after discharge, abdominal pain and fever persisted, hemoglobin $11.3 \mathrm{~g} / \mathrm{dL}$, leukocytes $10 \times 10^{3} / \mathrm{uL}$, eosinophils $1305 / \mathrm{uL}$, absolute neutrophil count 5321/uL, lymphocytes $2710 / \mathrm{uL}$, platelets $606 \times 10^{3} / \mathrm{uL}$, c-reactive protein $8.2 \mathrm{mg} / \mathrm{dL}$, fibrinogen $664 \mathrm{mg} / \mathrm{dL}$, dimer D $2 \mathrm{ug} / \mathrm{mL}$, ferritin $1030 \mathrm{ng} / \mathrm{mL}$, lactate dehydrogenase $890 \mathrm{U} / \mathrm{L}$, coagulation profile, urea, creatinine, and serum electrolytes were normal. Immunological tests were performed: negative antinuclear antibodies (ANA), negative anti-dsDNA, negative anti-neutrophil cytoplasmic antibodies (ANCA), negative anti-cyclic citrullinated peptide antibodies (anti-CCP), negative rheumatoid factor, negative lupus antibody and negative antiphospholipid profile, negative IgG antibodies against Toxocara. He received treatment with methylprednisolone at a dose of $2 \mathrm{mg} / \mathrm{kg} / \mathrm{day}$ for 7 days and then at a dose of $30 \mathrm{mg} / \mathrm{kg}$ for 3 days, then prednisone $2 \mathrm{mg} / \mathrm{kg} /$ day for 15 days. During his hospitalization he presented a decrease of abdominal pain and absence of fever, being discharged with the indication of controls by rheumatology.

He was readmitted to the pediatric emergency room 4 months later, with 12 days of evolution characterized by fever, abdominal pain, and generalized edema. On admission, he presented a heart rate of 140 beats/minute, respiratory rate 29/minute, blood pressure (p90-95). He presented edema of the face, genitals, hands, and feet. The skin was cold, turgid with erythematous macular lesions of urticariform appearance (positive dermographism) associated with diffuse hematic crusts and fine desquamation on face, neck, thorax, arms, and legs. Examinations found hemoglobin $11.6 \mathrm{gr} / \mathrm{dL}$; platelet count $170 \times 10^{3} / \mathrm{uL}$; prothrombin time (PT) $13.1 \mathrm{sec}$, INR 1.1; activated partial thromboplastin time (aPTT) $34 \mathrm{sec}$, fibrinogen $432 \mathrm{mg} / \mathrm{dL}$, urea $16 \mathrm{mg} / \mathrm{dL}$, creatinine $0.34 \mathrm{mg} / \mathrm{dL}, \mathrm{D}$ - 
dimer $4.32 \mathrm{mg} / \mathrm{L}$, lactate dehydrogenase $1862 \mathrm{U} / \mathrm{L}$, serum calcium 7.2mg/dL, complement C3 120mg/dL, C4 28mg/dL, and hemoglobinuria. He was transferred to the dermatology department due to the dermatological lesions described. Three days later the dermal lesions increased (Fig. 1), a skin biopsy of the lesions was performed describing acute spongiotic dermatitis with intraepidermal vesicles and numerous necrotic keratinocytes in the epidermis, associated with superficial and deep perivascular and perianexial inflammatory infiltrate with numerous eosinophils and extravasation of red cells. The histochemical study with Periodic Acid Schiff and Alcian Blue was negative. He presented oligoanuria and generalized tonic-clonic seizure associated with desaturation $86 \%$ (fiO2 21\%) on three occasions. Due to unstable hemodynamic compromise, it was decided to perform endotracheal intubation and transfer him to the Pediatric Intensive Care Unit (PICU) for ventilatory and hemodynamic management. In PICU hemoglobin 10.6 g/dl, schistocytes $6+/$ field (blood), positive direct coombs test, leukocytes $13.4 \times 10^{3} / \mathrm{uL}$, platelets $19 \times 10^{3} / \mathrm{uL}$, haptoglobin not detectable, triglycerides $280 \mathrm{mg} / \mathrm{dL}$, ferritin $3442 \mathrm{ng} / \mathrm{mL}$, lactate dehydrogenase $1862 \mathrm{U} / \mathrm{L}$, D-dimer $4 \mathrm{mg} / \mathrm{L}$, complement C3 $120 \mathrm{mg} / \mathrm{dL}$ and C4 28mg/dL, creatinine 1,23 mg/dL), creatine kinase 248mg/dL, erythrocyte sedimentation rate $19 \mathrm{sec}$ and ADAMTS13 activity in 54\% (RV: 40-130\%) after transfusion support of blood products. Flow cytometry showed decreased T lymphocytes, CD4 + lymphocytes, CD8 + lymphocytes, increased CD4/CD8 ratio for age, and decreased NK cell count. The Viral load for Epstein Barr virus, Cytomegalovirus, and Parvovirus B19 was negative.

Renal ultrasound showed left kidney with asymmetry concerning the contralateral one and in the Doppler study, there was a decrease in the wave depth suggesting left renal hypoperfusion. With the clinical and laboratory manifestations described, the patient was diagnosed with TTP. The PLASMIC score was 7 (Table 1). He received fresh frozen plasma, renal replacement therapy, methylprednisolone cycles, human immunoglobulin, and rituximab (Table 1). Due to the persistence of severe thrombocytopenia, it was decided to initiate PEX receiving 14 sessions, before the plasma exchange, she received platelet transfusion to compensate for the platelet deficit, with poor response. During his stay in the PICU, he presented deterioration of the sensorium and intracerebral hemorrhage (after one month of the last PEX session) was found in the tomography. The patient had an unfavorable evolution and fatal outcome in the second month of hospitalization. The genetic panel of sequence analysis and deletion/duplication test of 13 genes (ADAMTS13, C3, CD46, CD55, CD59, CFB, CFH, CFI, DGKE, INF2, MMACHC, PLG, THBD) for atypical hemolytic uremic syndrome and thrombotic microangiopathy were negative.

\section{Discussion}

TTP in children is infrequent (3). Acquired TTP has been reported as a clinical presentation or associated with COVID-19 in adults (5), however, in children, there is limited cases report (6).

In the patient, on his first hospital admission, Multisystem Inflammatory Syndrome (MIS-C) was diagnosed, for that reason he received MIS-C therapy. Four months later, he was readmitted to the hospital with multiple organ damage, probably autoimmune, triggered by post-infection SARS-COV-2.

In some cases of acquired TTP with ADAMTS13 deficiency, antibodies may be undetectable, which could be related to the lack of sensitivity of the available methods (8), and sensitivity of anti-ADAMTS13 antibodies of IgM or IgA type (9), or due to an altered synthesis or secretion of ADAMTS13 (10). Our patient underwent ADAMTS13 dosing, after PEX, this procedure delivers deficient enzyme (ADAMTS13) and removes autoantibodies that inhibit ADAMTS13 activity, therefore, the result was interpreted in normal ranges. Additionally, we met features of microangiopathic hemolytic anemia (MAHA) associated with thrombotic microangiopathy (MAT) in the clinical context of anemia, reticulocytosis, schistocytosis, elevated lactate dehydrogenase, undetectable haptoglobin, hemoglobinuria, and severe thrombocytopenia.

The PLASMIC Score discriminated between PTT and other MAT, such as atypical uremic syndrome, reliably assesses the likelihood of a severe deficit of ADAMTS13 activity in patients with MAT and could help improve the accuracy of clinical assessment and be beneficial when ADAMTS13 testing is not available $(11,12)$. Gupta et al. report that PLASMIC score could also be a good predictor in children to identify patients with an ADAMTS13 activity less than $10 \%(13)$.

On admission to the PICU, we obtained a PLASMIC Score 7 in the patient (platelet count < 30,000 / microL, hemolysis, no active cancer, no solid organ or stem cell transplantation, no diarrhea, INR $<1.5$, creatinine $<2.0 \mathrm{mg} / \mathrm{dL}$ ). Therefore, the PLASMIC Score predicted ADAMST13 deficiency in the presence of a high degree of suspected TTP and guided the management of PEX according to the Score.

Reverse transcriptase-polymerase chain reaction (RT-PCR) for SARS-CoV-2 was negative on readmission but serological tests were positive SARS-CoV-2 IgG, similar to the report of a 14-year-old man with a past infection for SARS-COV-2 IgG who developed TTP, like our patient with a favorable evolution after PEX sessions (6).

In PICU, management was carried out with hemodynamic support, corticotherapy, immunoglobulin, rituximab, and fresh frozen plasma, obtaining a gradual response without being effective while waiting for the start of PEX, which began 11 days after the diagnosis of TTP. The use of immunosuppressive therapy together with PEX showed an improvement in the results, as well as decreases the days required for PEX and thus avoids the complications of this (14).

During the PEX, a partial response was evidenced with a decrease in MAHA and partial clinical improvement of the patient; however, due to lack of resources necessary to maintain the PEX, the patient only received 14 cycles without achieving the objective of platelet count greater than $150 \times 10^{3} / u L$ in two controls or more days as a cut-off point to finish the PEX (Table 1). PEX is used in patients with a presumptive or confirmed clinical diagnosis of TTP. It is used in all patients because if it is not treated, it follows the progressive course of neurological deterioration or kidney failure. Mintz PD et al, through a clinical trial, have described the use of up to two cycles of PEX in patients with purpura thrombotic thrombocytopenia. In this study of seven patients with a second cycle of PEX, four achieved remissions (15). Another report described up to 25 daily PEX sessions were used without complications and favorable evolution (6). A recent study on the use of PEX in PICU in Chile reported complications related to the apheresis circuit, hypotension, anaphylaxis, or transfusion-related acute lung injury (16). Although the mean number of PEX sessions in this study was lower than that used in our patient due to the different pathologies evaluated, no hemorrhagic complications were reported (16). 
The delay in starting treatment, coupled with premature discontinuation of PEX and suspicion of relapsed acquired TTP were the possible causes of the poor response to treatment, with severe renal and neurological compromise. The analysis of the evolution of the disease impressed MAT was partially treated with corticosteroids, immunomodulatory therapy with immunoglobulin, rituximab, and PEX. The genetic panel to rule out hereditary TTP, complement-associated hemolytic uremic syndrome, and alterations in vitamin B12 metabolism was negative, confirming acquired TTP.

In a similar approach to the systemic hyperinflammatory syndrome in children, caused six weeks after exposure to SARS-CoV-2, there are few reports defining different times between viral exposure and the presentation of thrombotic thrombocytopenic purpura. It has also been associated with infection by Dengue virus, Cytomegalovirus, Epstein Barr, which leads to thrombotic thrombocytopenic purpura that can vary between 10 days to 3 months, the time of presentation in the case of SARS-CoV-2 is a matter of investigation, that is why the importance of this case report.

The limitation of this report is that there is not enough evidence in the literature to conclude that the acquired TTP was caused by the immune response to SARS-CoV-2. Further studies are required to confirm the existence of a causal factor between these two conditions.

In conclusion, the presentation, and clinical course of acquired TTP associated with SARS-CoV-2 was severe. Early diagnosis and rapid initiation of combined treatment are important to obtain better prognoses.

\section{References}

1. Lu E, Moore W. The PLASMIC Score May Be Useful in the Early Diagnosis of Complement-Mediated Thrombotic Microangiopathy via Early Exclusion of Thrombotic Thrombocytopenic Purpura. Case Rep Med. 2019:e9180810.

2. Tehrani HA, Darnahal M, Vaezi M, Haghighi S. COVID-19 associated thrombotic thrombocytopenic purpura (TTP); A case series and mini-review. Int Immunopharmacol. 2021;93:107397.

3. Joly BS, Coppo P, Veyradier A. Pediatric thrombotic thrombocytopenic purpura. Eur J Haematol. 2018;101(4):425-34.

4. Sánchez-Tauma PJ, Atamari-Anahui N, Valera-Moreno C. Enfermedad por Coronavirus 2019, COVID-19: Aspectos a considerar en niños. Rev Cuerpo Méd HNAAA. 2020;13(1):88-94.

5. Taherifard E, Taherifard E, Movahed H, Mousavi MR. Hematologic autoimmune disorders in the course of COVID-19: a systematic review of reported cases. Hematol. 2021;26(1):225-39.

6. Hidalgo Filho CMT, Dalessandro Adamo DSM, Lopes CM, Martin EM. Thrombotic thrombocytopenic purpura associated with COVID-19 in a pediatric patient: case report. Hematol Transfus Cell Ther. 2021.

7. Verma DP, Dandu H, Yadav G, Verma SP. Complicated case of COVID-19 disease with overlapping features of thrombotic thrombocytopenic purpura and haemophagocytic lymphohistiocytosis. BMJ Case Rep. 2021;14(5).

8. Lotta LA, Valsecchi C, Pontiggia S, Mancini I, Cannavò A, Artoni A, et al. Measurement and prevalence of circulating ADAMTS13-specific immune complexes in autoimmune thrombotic thrombocytopenic purpura. J Thromb Haemost. 2014;12(3):329-36.

9. Ferrari S, Scheiflinger F, Rieger M, Mudde G, Wolf M, Coppo P, et al. Prognostic value of anti-ADAMTS 13 antibody features (Ig isotype, titer, and inhibitory effect) in a cohort of 35 adult French patients undergoing a first episode of thrombotic microangiopathy with undetectable ADAMTS 13 activity. Blood. 2007;109(7):2815-22.

10. Uemura M, Fujimura Y, Matsumoto M, Ishizashi H, Kato S, Matsuyama T, et al. Comprehensive analysis of ADAMTS13 in patients with liver cirrhosis. Thromb Haemost. 2008;99(6):1019-29.

11. Bendapudi PK, Hurwitz S, Fry A, Marques MB, Waldo SW, Li A, et al. Derivation and external validation of the PLASMIC score for rapid assessment of adults with thrombotic microangiopathies: a cohort study. Lancet Haematol. 2017;4(4):e157-64.

12. Li A, Khalighi PR, Wu Q, Garcia DA. External validation of the PLASMIC score: a clinical prediction tool for thrombotic thrombocytopenic purpura diagnosis and treatment. J Thromb Haemost. 2018;16(1):164-9.

13. Gupta GK, Hendrickson JE, Tormey CA. Application of PLASMIC score in prediction of ADAMTS13 deficiency in a pediatric case of acquired thrombotic thrombocytopenic purpura. J Clin Apheresis. 2020;35(2):140-1.

14. Som S, Deford CC, Kaiser ML, Terrell DR, Kremer Hovinga JA, Lämmle B, et al. Decreasing frequency of plasma exchange complications in patients treated for thrombotic thrombocytopenic purpura-hemolytic uremic syndrome, 1996 to 2011. Transfusion. 2012;52(12):2525-32; quiz 2524.

15. Mintz PD, Neff A, MacKenzie M, Goodnough LT, Hillyer C, Kessler C, et al. A randomized, controlled Phase III trial of therapeutic plasma exchange with fresh-frozen plasma (FFP) prepared with amotosalen and ultraviolet A light compared to untreated FFP in thrombotic thrombocytopenic purpura.

Transfusion. 2006;46(10):1693-704.

16. Bustos B R, Hickmann O L, Cruces R P, Díaz F. Therapeutic plasma exchange in critically ill children: experience of the pediatric intensive care unit of two centers in Chile. Transfus Apher Sci. 2021;103181.

\section{Declarations}

Conflict of Interest Disclosures: The authors Jesús Domínguez, William Campano, Jaime Tasayco, Andrea Siu Lam, Cesia Ortega Ocas, Noé Atamari-Anahuid, have indicated they have no conflicts of interest relevant to this article Refractory thrombotic purpura thrombocytopenic acquired by SARSCoV-2 in critical child: Case report.

\section{Tables}


TABLE 1. Laboratory values during hospitalization.

\begin{tabular}{|c|c|c|c|c|c|c|c|c|c|c|}
\hline $\begin{array}{l}\text { Hospital } \\
\text { admissions }\end{array}$ & 1 st & 2nd & $3 r d$ & \multicolumn{7}{|c|}{$3 r d$} \\
\hline Departament & Medicine & Medicine & Dermatology & \multicolumn{7}{|c|}{ PICU } \\
\hline Hospitalization day & 1 & 1 & 1 & $1 *$ & $3+$ & 11 & 16 & 23 & 30 & 37 \\
\hline Treatment & & & & & $\begin{array}{l}\mathrm{MTP}+\mathrm{IG} / \\
\text { Rtmb/DP }\end{array}$ & $\begin{array}{c}\text { MTP/PEX/ } \\
\text { DP }\end{array}$ & $\begin{array}{c}\text { MTP/Rtmb/ } \\
\text { PEX/HD }\end{array}$ & $\begin{array}{c}\text { PDN/Rtmb/ } \\
\text { PEX/HD }\end{array}$ & $\begin{array}{c}\text { PDN/Rtmb/ } \\
\text { HD }\end{array}$ & $\begin{array}{c}\mathrm{PDN} / \\
\mathrm{HD}\end{array}$ \\
\hline \multicolumn{11}{|l|}{ Laboratory } \\
\hline \multicolumn{11}{|l|}{ Haematology } \\
\hline Hemoglobin (g/dL) & 13,3 & 11,3 & 11,6 & 10,6 & 8 & 10 & 7,8 & 9,1 & 7,8 & 8,4 \\
\hline $\begin{array}{l}\text { Leukocytes } \\
\left(10^{3} / \mathrm{uL}\right)\end{array}$ & 18,9 & 10 & 16,4 & & 9,2 & 17,4 & 11,6 & 5,4 & 2,2 & $\overline{5,3}$ \\
\hline Platelets $\left(10^{3} / \mathrm{uL}\right)$ & 528 & 606 & 170 & 19 & 14 & 68 & 40 & 32 & 99 & 51 \\
\hline $\begin{array}{l}\text { Prothrombin Time } \\
\text { (seconds) }\end{array}$ & 12,8 & 12,4 & 13 & 16 & 13 & 12,4 & 13,1 & 13,5 & -- & $\overline{13,8}$ \\
\hline INR & 1,1 & 1,0 & 1,1 & 1,4 & 1,1 & 1 & 1,1 & 1,1 & - & $\overline{1,2}$ \\
\hline $\begin{array}{l}\text { Thromboplastin } \\
\text { Time (seconds) }\end{array}$ & 29,6 & 28,5 & 34 & 44 & 29 & 33,5 & 37,2 & 43,7 & - & $\overline{42,7}$ \\
\hline $\begin{array}{l}\text { Thrombin } \\
\text { time (seconds) }\end{array}$ & 17 & 17 & 18,7 & 27 & 23 & 21 & 19,8 & 25,8 & -- & 24 \\
\hline $\begin{array}{l}\text { Fibrinogen } \\
(\mathrm{mg} / \mathrm{dL})\end{array}$ & 581,3 & 664 & 432 & 300 & 335 & 230 & 253,4 & 226,6 & -- & 164,1 \\
\hline D-dimer (mg/L) & 1,6 & 2,0 & 4,32 & 6,8 & 12,2 & -- & -- & 3,6 & - & \\
\hline \multicolumn{11}{|l|}{ Biochemical } \\
\hline Ferritin $(\mathrm{ng} / \mathrm{mL})$ & 1016 & 1030 & -- & 3442 & 23943 & 3254 & -- & -- & - & -- \\
\hline C3 (mg/dL) & 101 & & 120 & -- & & -- & -- & -- & -- & -- \\
\hline $\mathrm{C} 4$ (mg/dL) & 24 & 32 & 28 & -- & & -- & - & - & - & - \\
\hline $\begin{array}{l}\text { Lactate } \\
\text { Dehydrogenase } \\
(\mathrm{U} / \mathrm{L})\end{array}$ & 1317 & 890 & 1862 & -- & 10562 & 2279 & 1780 & 754 & 494 & - \\
\hline Urea $(\mathrm{mg} / \mathrm{dL})$ & 18 & 23 & 16 & 49 & 173 & 177 & 245 & 84 & 54 & 57 \\
\hline Creatinine (mg/dL) & 0,40 & 0,32 & 0,34 & 1,23 & 4 & 3,6 & 4,14 & 1,9 & 1,8 & 1,8 \\
\hline TGO (U/L) & 34 & 50 & 48 & 233 & 360 & -- & -- & 32 & - & -- \\
\hline TGP (U/L) & 17 & 49 & 9 & 61 & - & -- & -- & 42 & - & -- \\
\hline CPK (mg/dL) & & 44 & 248 & -- & 1883 & -- & -- & 31 & - & -- \\
\hline CPK-MB (U/L) & 25 & 14 & 26 & -- & 102 & -- & -- & 12 & - & -- \\
\hline $\begin{array}{l}\text { Protein C } \\
\text { Reactive }(\mathrm{mg} / \mathrm{dL})\end{array}$ & 4,61 & 8,17 & 4,76 & 5,9 & 6 & 2,6 & - & 2,2 & - & $\overline{12,8}$ \\
\hline
\end{tabular}

(*) PLASMIC Score: Platelet count <30,000/microL: 1, Hemolysis: 1, No active cancer: 1, No solid organ transplantation or stem cells: 1, MCV <90 fl / No diarrheas 1, INR <1.5: 1, Creatinine <2.0 mg/dL: 1 (Score 7). Corticosteroid onset: methylprednisolone (MTP) 1gr plus immunoglobulin 5\% 30gr for 5 days, it was then decreased to methylprednisolone $125 \mathrm{mg}$ every 6 hours for 5 days and methylprednisolone $125 \mathrm{mg}$ every 8 hours for 5 days, then moved to prednisone (PDN) $1 \mathrm{mg} / \mathrm{kg}$ equivalent dose in dexamethasone. 
Initiation of rituximab (Rtmb) 375mg/m2/dose each week (4 doses). (+) Indication of fresh frozen plasma 10cc/kg/dose every 8 hours. PEX: Plasma exchange: received 14 cycles. DP: Peritoneal dialysis. HD: hemodialysis.

\section{Figures}

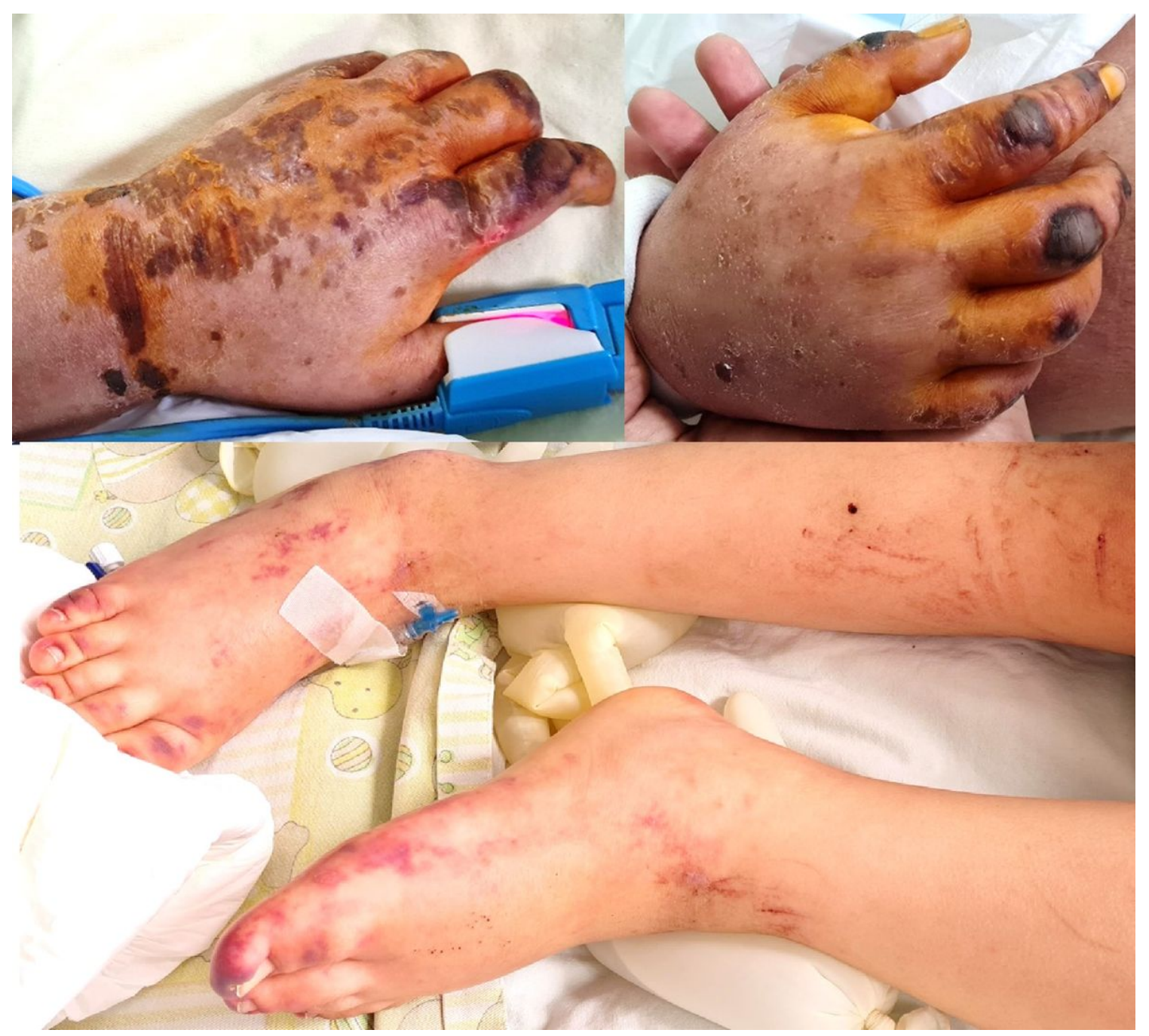

Figure 1

Erythematous macular lesions associated with excoriative hematic scabs in hands on the day of PICU admission associated with purpuric dermatosis in lower limbs. 